\title{
O PLANEJAMENTO PEDAGÓGICO NOS CURSOS DE GRADUAÇÃO DA UFTM
}

\author{
PEDAGOGICAL PLANNING IN UFTM GRADUATE COURSES
}

PLANIFICACIÓN PEDAGOGICA EN LOS CURSOS SUPERIORES DE LA UFTM

Eliana Helena Corrêa Neves Salge

E-mail: eliana.salge@uftm.edu.br

Giselle Abreu de Oliveira

E-mail: giselle.oliveira@uftm.edu.br

Liliane Carla Campos

E-mail: liliane.campos@uftm.edu.br

Camila Cunha Oliveira Giordani

E-mail: camila.giordani@uftm.edu.br

Universidade Federal do Triângulo Mineiro - UFTM

\section{RESUMO}

O presente artigo tem por objetivo analisar, à luz de referenciais teóricos que abordam o planejamento no âmbito educacional, a primeira experiência de Planejamento Pedagógico Semestral, realizada pelos cursos de graduação da Universidade Federal do Triângulo Mineiro, após a publicação de normativa que institui a obrigatoriedade de tal atividade. A discussão se faz necessária tendo em vista a importância do planejamento para o processo ensino-aprendizagem e a necessidade de fomentar reflexões que contribuam para que os sujeitos se comprometam com o planejamento coletivo participativo. Assim, a partir de pesquisa bibliográfica, análise documental e dados coletados em questionário semi-aberto, pudemos confirmar a importância do planejamento pedagógico no âmbito dos cursos de graduação e perceber que a participação dos sujeitos constitui um dos maiores entraves para sua efetiva realização.

PALAVRAS-CHAVE: Planejamento Pedagógico. Projeto Pedagógico. Cursos de Graduação.

ABSTRACT

This article intends to analyze, with the theoretical references that study educational planning, the first experience of Semester Pedagogical Planning made by the undergraduate courses of the Federal University of the Triangulo Mineiro, after the norm that requires this. It is necessary to discuss this, because planning is important for the teaching-learning process. Besides, it is important to think about the need for people to commit to participatory and collective planning. So, using bibliographic research, documentary analysis and a semi-open questionnaire, we have confirmed the importance of the pedagogical planning in undergraduate courses and we realize that the participation of people is one of the mains difficulties in planning.

KEYWORS: Pedagogical Planning. Pedagogical Project. Undergraduate Courses.

\section{RESUMEN}

El objetivo de este artículo es analizar, a la luz de las referencias teóricas que obordan la planificación en el campo educativo, la primera experiencia de Planificación Pedagógica para los semestres, realizada por los Cursos Superiores em la Universidade Federal do Triângulo Mineiro, después de la publicación de la normativa que establece la obligación de la actividad. La discusión es necesaria considerando la importância de la programación para el proceso de ensenãnza-aprendizaje y la necesidad de fomentar reflexiones que contribuyan a que los sujetos se comprometan com la planificación colectiva y participativa. Así, a partir de la investigación bibliográfica, el análisis de documenos y los datos recopilados en um cuestionario semiabierto, pudimos confirmar la importancia de la planificación pedagógica em los Cursos Superiores y danos cuenta de que la participación de los sujetos constituye uno de los mayores obstáculos para su realización efectiva. 


\section{INTRODUÇÃO}

Planejar é ação indispensável para o sucesso do processo ensino-aprendizagem nos diversos níveis de ensino, conforme afirmam Alarcão (2015), Arruda (2015), Vasconcelos (2007), Veiga (2004) e outros, perpassando não apenas a gestão das universidades, mas também os cursos de graduação e, inclusive, a sala de aula. Na verdade, planejar é essencial a quaisquer atividades humanas, a fim de que se tenha intencionalidade e significado nas ações. A frase atribuída ao filósofo Sêneca (4 a.C - 65 d.D) já dizia que "não há vento favorável para quem não sabe para onde ir", ilustrando que, sem planejamento, não há direcionamento.

Assim, planejar é, em poucas palavras, definir um "ponto de chegada" e traçar estratégias que possam levar até lá. Planejamento pedagógico, portanto, seria pensar em tal tarefa do ponto de vista das questões pedagógicas. É pensar em ações e características que permitam o cumprimento de propósitos e intencionalidades ligados à formação dos sujeitos. (VEIGA, 2002). Sobre essa dimensão pedagógica, Alarcão (2015, p.9) acrescenta:

A conscientização de que os professores universitários também precisam pensar a pedagogia começou a emergir nos anos 70/80 do século passado [...] A razão que emerge com mais força tem a ver com a grande expansão que se verificou no ensino superior, a sua democratização, com tudo que esse fenômeno político-social envolve [...] Não bastava agora ser cientificamente bom para conseguir criar condições de aprendizagem e de desenvolvimento a uma massa heterogênea de alunos.

Partindo desta compreensão, o planejamento é ferramenta essencial para que os docentes busquem, coletivamente e participativamente, pensar as relações com o saber e sua construção, suas práticas pedagógicas e o currículo proposto. Sem tempos e espaços destinados ao planejamento coletivo, corre-se o risco de que professores trabalhem de forma desarticulada, realizando atividades por vezes isoladas e que não favorecem a interdisciplinaridade.

Deve-se pensar o problema do ensino considerando que a dicotomia dos saberes e a desarticulação entre eles não contribui para o desenvolvimento da potencialidade da mente humana. A contextualização e a integração são premissas que precisam ser mais bem trabalhadas (produzindo sentido) e não tolhidas (MORIN, 2003). Dessa forma, "é preciso substituir um pensamento disjuntivo e redutor por um pensamento complexo, no sentido originário do termo complexus: que é tecido junto" (MORIN, 2003, p.89, itálico do autor).

Na perspectiva da articulação, o planejamento pedagógico de um curso de graduação se faz 
a partir de um contexto maior no qual se insere. Aí se destaca o papel das políticas públicas nacionais, que se materializam por meio de Leis Federais, Programas, Resoluções do Ministério da Educação - tais como as Diretrizes Curriculares Nacionais, que orientam a constituição dos cursos de graduação -, bem como por meio de políticas institucionais propostas pela Instituição de Ensino Superior (IES), sistematizadas e apresentadas em documentos como o Plano de Desenvolvimento Institucional (PDI) e Projeto Pedagógico Institucional (PPI).

As ações de planejamento educacional, portanto, encontram preceito na Lei n. ${ }^{\circ}$ 9.394, de 20 de dezembro de 1996, Lei de Diretrizes e Bases da Educação Nacional (LDB), estando baseadas em princípios como pluralismo de ideias e de concepções pedagógicas, gestão democrática, garantia de padrão de qualidade, dentre outros. A LDB atribui, ainda, aos estabelecimentos de ensino a função de elaborar sua proposta pedagógica (art. 12, inciso I) e estabelece, em seu art. 13, que cabe aos professores participarem desse processo. Tais dispositivos relacionam-se ao princípio da autonomia universitária prevista no art. 207 da Constituição Federal e ao princípio do pluralismo de ideias e de concepções pedagógicas que consta no art. 206 da referida Lei.

Destaca-se também o Decreto n. ${ }^{\circ}$ 9.235, de 15 de dezembro de 2017, que dispõe sobre o exercício das funções de regulação, supervisão e avaliação das instituições de educação superior e dos cursos superiores de graduação e de pós-graduação no Sistema Federal de Ensino. Este apresenta, em seu art. 20, a obrigatoriedade de a instituição de ensino superior constituir, entre seus documentos essenciais, o PDI, ao qual se integra o PPI. Ambos expressam o planejamento e as formas de gestão da universidade e amparam a realização do planejamento pedagógico de forma coletiva e periódica. O PDI é o principal instrumento de planejamento estratégico da instituição, a ser desenvolvido em um período de cinco anos, considerando a identidade da universidade no que diz respeito à sua missão, objetivos e metas propostas, que devem ser alcançados pelas diversas unidades acadêmicas e setores administrativos. Expressa também o planejamento estratégico da instituição em termos de ações promotoras do desenvolvimento e da expansão da universidade. A ele se integra o projeto pedagógico da instituição de ensino, que deve conter, dentre outros aspectos, as diretrizes das suas políticas institucionais de ensino, pesquisa e extensão. Nesse contexto, o PPI explicita as concepções de ser humano, de mundo e de educação da universidade, sendo a "carta magna" da constituição pedagógica de uma proposta educacional de nível superior. Mais do que um simples documento técnico-burocrático, deve ser considerado como um instrumento de ação política e pedagógica, 
destinado a garantir "uma formação global e crítica para os envolvidos no processo, como forma de capacitá-los para o exercício da cidadania, a formação profissional e o pleno desenvolvimento pessoal" (VEIGA, 2004, p.16).

Assim o PPI deve centrar-se em uma função política, capaz de destacar a educação como fator de superação e desenvolvimento humano, considerando a busca constante da qualidade da educação ofertada e a construção de uma sociedade democrática. As diretrizes da política de ensino que fazem parte do PPI/UFTM 2017-2021 corroboram a importância do Planejamento Pedagógico Semestral na instituição, uma vez que o ensino constitui uma das atividades-fim da universidade. Destacam-se cinco diretrizes:

- Promover e valorizar processos educativos pautados no diálogo, como instrumento de exercício e de efetivação da gestão cidadã e democrática, de forma que professores e estudantes se sintam acolhidos e respeitados em suas demandas no âmbito do ensino;

- Valorizar a educação na, e para a diversidade, via práticas educativas que respeitem a diversidade humana em todos os seus aspectos físicos, culturais, psicológicos e sociais.

-Estimular as práticas de ensino inovadoras que promovam atitudes de aprender a conhecer, a fazer, a conviver e a ser, focando a articulação constante entre teoria e prática em todas as áreas do conhecimento.

-Incentivar a utilização de metodologias ativas de ensino-aprendizagem, por meio das quais se desenvolva a autonomia e a criticidade do aluno e a garantia de ações voltadas para a oferta de novas oportunidades de aprendizagem ao longo do período letivo, visando à diminuição dos índices de evasão e retenção dos alunos.

- Promover a utilização de avaliações do ensino de forma ampla, contínua, gradual, dinâmica, cooperativa e cumulativa, assumindo, de forma integrada, as funções diagnóstica, formativa, mediadora e somativa, com preponderância dos aspectos qualitativos sobre os quantitativos (UFTM, 2018, s./p.).

Vale lembrar que as ações dos cursos de graduação devem, portanto, respeitar os pressupostos filosóficos e conceituais da universidade, instituídos por meio do seu PPI.

Infere-se que as políticas nacionais e institucionais, desse modo, devem ser coesas e corroborar para a formação de cidadãos-profissionais que auxiliem na construção de um país cada vez mais ético, rico socioeconomicamente e comprometido com o bem estar biopsicossocial de sua população. Assim, o planejamento pedagógico dos cursos precisa considerar, dentre outros aspectos, estes referenciais, para que haja coerência nas ações propostas.

Nessa direção, a primeira experiência de planejamento pedagógico no âmbito do curso de graduação é a elaboração de seu Projeto Pedagógico de Curso (PPC). 
Os PPC [...] devem trazer a inter-relação com o PPI e o PDI. Os projetos de curso materializam as diretrizes, filosofias e pressupostos das políticas pedagógicas propostas pela instituição, sendo responsáveis diretos pela qualidade da formação oferecida pelas instituições de educação superior (HAAS, 2010, p.166).

Portanto, o PPC é o primeiro instrumento de planejamento coletivo e participativo construído no cerne do curso e será abordado na seção 2 deste artigo. Por hora, adiantamos que o PPC é o instrumento que explicita os objetivos do curso, bem como o perfil profissional do egresso, ou seja, é ele que define o "local de chegada" do curso. A partir dessas definições, o PPC traça caminhos possíveis para que se chegue ao "destino" desejado e permite que o curso planeje ações de curto prazo que também concorram para esse objetivo.

Pensando neste planejamento pedagógico, a Universidade Federal do Triângulo Mineiro (UFTM), recentemente, aprovou uma normativa interna, Decisão Normativa n. ${ }^{\circ}$ 24/2018, que institui o Planejamento Pedagógico Semestral em todos os cursos de graduação, devendo ser feito antes do início de cada semestre letivo.

A partir dos referenciais teóricos que abordam a temática e de questionários semi-abertos, aplicados aos coordenadores de cursos, buscou-se compreender qual o significado e a contribuição do planejamento pedagógico para os cursos de graduação da UFTM.

Desta forma, intentamos contribuir para o fortalecimento de uma visão de planejamento pedagógico que considere a importância do trabalho coletivo, da participação dos diferentes sujeitos e da reflexão da prática docente como ponto de partida para seu constante aprimoramento.

\section{REFERENCIAL TEÓRICO}

\subsection{Projeto Pedagógico de Curso (PPC): planejar para transformar}

A palavra projeto deriva do latim projectus, cujo significado tem a ver com algo que é lançado para frente, que se move de um local presente para um local futuro. Segundo o Dicionário Michaelis, a palavra projeto pode significar "1 propósito de executar algo; 2 Plano detalhado de um empreendimento a ser realizado [...]; 4 Esboço de trabalho que se pretende realizar"1.

Machado (2006, p.1-2) afirma que:

\footnotetext{
${ }^{1}$ Fonte disponível em: $<\mathrm{http}: / /$ michaelis.uol.com.br/busca? $\mathrm{r}=0 \& \mathrm{f}=0 \& \mathrm{t}=0 \&$ palavra=projeto $>$. Acesso em: $11 \mathrm{mar}$. 2019.
} 
Projetam todos os que estão vivos, todos os que antecipam cursos de ação, os que concebem transformações de situações existentes em outras imaginadas e preferidas, elegendo metas a serem perseguidas, tanto em termos pessoais quanto em termos coletivos, o que situa a idéia de projeto no terreno próprio do exercício da cidadania.

Projeto, portanto, é aquilo que faz referência ao futuro, que antecipa, de alguma forma, situações que exijam determinadas estratégias no presente. Nessa direção, quanto ao PPC, Vasconcellos (2007, p.169) o define como sendo

a sistematização, nunca definitiva, de um processo de Planejamento Participativo, que se aperfeiçoa e se concretiza na caminhada, que define claramente o tipo de ação educativa que se quer realizar. É um instrumento teórico-metodológico para a intervenção e mudança da realidade.

Infere-se, portanto que o PPC é projeto porque olha para o presente buscando caminhos e ferramentas para transformá-lo, e é pedagógico porque define "as ações educativas e as características necessárias às escolas de cumprirem seus propósitos e sua intencionalidade" (VEIGA, 2002, p.1). Do mesmo modo, apesar de não carregar o termo político em sua nomenclatura, todo Projeto Pedagógico, da escola básica à universidade, é político, "no sentido de compromisso com a formação do cidadão para um tipo de sociedade" (VEIGA, 2002, p.1). Construir um PPC tem, nessa perspectiva, um caráter de compromisso com um futuro que se pretende criar, do ponto de vista pedagógico, mas também político e social.

Assim, projetar não diz respeito a fazer previsões sobre o futuro, mas a determinar ações que visem criar a futuro em uma relação planejamento-ação. Para Barbier (1994 apud MACHADO, 2006, p.6), “o projeto não é uma simples representação do futuro, do amanhã, do possível, de uma idéia; é o futuro a fazer, um amanhã a concretizar, um possível a transformar em real, uma idéia a transformar em acto".

Do mesmo modo, um projeto precisa considerar que o futuro refere-se ao novo, àquilo que se deseja, mas que ainda não é real. Projetar é imaginar o amanhã com criatividade e, ao mesmo tempo, com realismo, para que o "local de chegada" não seja desmotivante e tampouco inalcançável. Aqui, acrescenta-se que o novo não é uma ambição ensimesmada, ou seja, não se busca o novo pelo novo a qualquer preço, mas um novo que transforme aquilo que se acredita necessário de ser transformado. Por isso, para se ter a compreensão do que precisa ser mudado e construir um planejamento coerente é importante analisar e avaliar o presente, o contexto em que está inserido o PPC. Para Vasconcellos $(2007$, p.104) a análise da realidade envolve o "esforço investigativo (e 
hermenêutico) no sentido de captar e entender a realidade, tal qual se encontra no presente, sua articulação histórica, em vista de sua transformação".

Nessa direção, a avaliação é uma ferramenta importante, pois auxilia no processo de tomada de decisões e não se restringe a um momento específico. Ao contrário, precisa ser uma prática constante, com finalidade diagnóstica e que permita a compreensão da realidade universitária, bem como do próprio curso de graduação. A prática avaliativa favorece o acompanhamento e a revisão dos passos que já foram, ou precisam ser dado, rumo à concretização dos objetivos definidos pelo coletivo.

Infere-se, portanto, que planejar é ação humana dependente de sujeitos que se comprometam com sua materialização. Não se pode fazer projetos para que outras pessoas o executem, pois assim como um projeto de vida é pessoal e intransferível, um projeto no campo da educação precisa ser pensado e desenvolvido por sujeitos interessados nele. Se o projeto nasce de um desejo de futuro, só quem tem o desejo pode projetar e agir para que ele se concretize.

Parente (2010), ao abordar o planejamento estratégico no campo da educação, destaca que, em concepções tradicionais de planejamento, as decisões eram tomadas pelo gestor ou grupo de gestores e compartilhadas com os demais sujeitos envolvidos. Esta compreensão tradicional e tecnicista de planejamento, com características tayloristas, muito utilizada no Brasil durante a ditadura militar (ARRUDA, 2015), vem sendo superado ao longo dos anos. Hoje, existem mecanismos, até mesmo legais, que visam garantir a participação da comunidade acadêmica na gestão de escolas e universidades. Tais espaços devem ser aproveitados como forma de se exercer cidadania e até mesmo resistência a modelos educacionais que pareçam impostos e imutáveis.

No caso do PPC, trata-se de um documento obrigatório que deve, necessariamente, ser elaborado, acompanhado e avaliado por um grupo de docentes denominado Núcleo Docente Estruturante (NDE). O NDE foi instituído pela Resolução CONAES n. ${ }^{\circ}$ 01, de 17 de junho de 2010, e visa, dentre outros aspectos, garantir que o PPC seja elaborado de forma participativa. Além disso, como o NDE não é órgão deliberativo, o PPC precisa ser discutido e aprovado, no mínimo², pelo Colegiado de Curso, que agrega representantes de diferentes categorias, incluindo os alunos.

O funcionamento destas instâncias de participação é objeto de avaliação pelo MEC/INEP3 em situações de avaliação externa do curso para fins de reconhecimento e renovação de

\footnotetext{
${ }^{2}$ Diz-se "no mínimo" porque, no caso da UFTM, por exemplo, o PPC precisa ser aprovado ainda pelo Conselho de Ensino, que agrega todos os coordenadores de cursos de graduação e outros profissionais, bem como pelo Conselho Universitário, composto por representantes de todos os segmentos da instituição e por pessoas da comunidade.

${ }^{3}$ MEC: Ministério da Educação / INEP: Instituto Nacional de Estudos e Pesquisas Educacionais Anísio Teixeira.
} 
reconhecimento, por exemplo. Desta forma, busca-se criar mecanismos que garantam a participação coletiva no planejamento do curso e na sua implementação. O PPC, "construído participativamente, é uma tentativa, no âmbito da educação, de resgatar o sentido humano, científico e libertador do planejamento" (VASCONCELLOS, 2007, p.169).

Outra questão importante que ganha destaque com a instituição dos NDE é a necessidade de constante revisão dos PPC. $\mathrm{O}$ art. $1^{\circ}$ da Resolução CONAES n. ${ }^{\circ}$ 01/2010 determina que deve haver contínua atualização do PPC. Assim, fica claro que o planejamento não é uma camisa de forças, estando sujeito a alterações, falhas, melhorias e mudanças de concepções e estratégias.

O planejamento precisa permitir o entrelaçamento da realidade diária - contexto concreto com os ideais dos atores educacionais. Dessa maneira, mesmo sendo constituído em um momento específico, o planejamento deverá ser revisitado e reformulado sempre que os sujeitos julgarem necessário e/ou houver a ocorrência de eventos inesperados que justifiquem a redefinição dos objetivos e metas do plano.

De fato, uma concepção rigorosamente determinística do real elimina completamente a idéia de projeto [...] Certa abertura para o desconhecido, para o não-determinado, para o universo das possibilidades, da imaginação, da criação, para o risco do insucesso são ingredientes necessários (MACHADO, 2006, p.6).

Por isso, compreende-se que o PPC, enquanto planejamento, precisa ser flexível, para que não se perca com um fim em si mesmo. Nesse sentido, destaca-se a importância de que o PPC seja constantemente avaliado, para que se conheça em que aspectos o curso avançou e em que precisa definir novas estratégias ou, até mesmo, mudar o "local de chegada".

Como dito anteriormente, este "ponto de chegada" pode ser definido como o perfil profissional do egresso que se quer formar, ou as competências e habilidades técnicas e humanas que o egresso poderá desenvolver ao longo do curso e que serão empregadas e aperfeiçoadas no mundo do trabalho.

Este perfil é fruto também de planejamento, pois, apesar de ter aspectos centrais definidos pelas Diretrizes Curriculares Nacionais de cada curso, é pensado pelo grupo de acordo com o perfil de egressos da universidade, conforme as demandas sociais, políticas e econômicas locais e regionais, bem como de acordo com as concepções de homem, mundo, sociedade, trabalho, educação e currículo que o curso defende.

Desta forma, o planejamento pedagógico, por meio do PPC, perpassa ainda as concepções filosóficas que embasam o perfil profissional que se deseja construir. Este "local de chegada" 
almejado é que permite traçar os objetivos do curso quanto à sua inserção política, social e econômica.

Com isso, a partir dos objetivos definidos, pensa-se nos caminhos para alcançá-los, ou seja, na organização curricular, nas metodologias de ensino-aprendizagem, nos processos avaliativos e outros que, em coerência com as concepções filosóficas, instrumentalizam o grupo para a construção do futuro desejado.

Nessa direção, as concepções filosóficas são a essência e a intencionalidade do planejamento, dando-lhe sentido. Sobre isso, Machado (2016) lembra que os debates em torno da educação privilegiam os aspectos econômicos, não obstante termos inúmeros indicadores numéricos que se apresentam como retratos da educação brasileira. No entanto, as concepções filosóficas tiram o planejamento de uma lógica utilitarista e dão a ele substância para analisar o presente e projetar o futuro com base em idéias de sociedade e ser humano.

Destarte, alinhavando a compreensão do presente, o desejo legítimo de transformar a realidade e as concepções filosóficas, o curso define, participativamente, ações que permitirão o alcance de seus objetivos. No entanto, esse é um planejamento macro que precisa se desdobrar em subplanejamentos, visando ao estabelecimento de ações em curto prazo.

Assim, em coerência com seu PPC, os cursos devem realizar seus Planejamentos Pedagógicos Semestrais na UFTM, que, por sua vez, poderão subsidiar os Planos de Ensino 4 e outros planejamentos e projetos do curso e das disciplinas.

\subsection{Planejamento Pedagógico periódico}

Se o PPC é o norteador das ações desenvolvidas pelo curso, o Planejamento Pedagógico Semestral, como um de seus desdobramentos, precisa seguir os mesmos princípios, ou seja, precisa olhar para a realidade, definir aonde se quer chegar ao futuro e traçar os caminhos possíveis. Tudo isso deve ser feito de forma participativa, guardando coerência em relação às concepções filosóficas do PPC e seus outros elementos.

Para Arruda (2015), a questão que se coloca é que muitos professores têm resistência ao planejamento pedagógico, sendo, por vezes, visto como atividade meramente burocrática e sem impacto direto no processo ensino-aprendizagem. Quanto a isso, a autora afirma ainda que tal

\footnotetext{
4 "Plano de Ensino é o instrumento norteador do planejamento didático-pedagógico dos componentes curriculares constantes nas Matrizes Curriculares dos Cursos de Graduação da UFTM”(UFTM, 2018, p.1).
} 
resistência pode ser um resquício da oposição ao modelo tradicional utilizado no Brasil durante a ditadura militar. Esse modelo, inspirado em concepções tayloristas e tecnicistas de eficácia, eficiência e produtividade, geraram em muitos professores um sentimento de aversão às atividades de planejamento, sobretudo, as coletivas.

Nesse período prevaleceu o planejamento como mecanismo de padronização e controle do trabalho dos professores, privilegiando, sobremaneira, a forma, a redação técnica e os formulários, em detrimento do conteúdo e dos fins da prática docente. Esta abordagem do planejamento favoreceu o desenvolvimento de práticas docentes individualistas, fragmentadas e promotoras da cópia, da reprodução, do silêncio e do ativismo (FARIA, 2011, p.109 apud ARRUDA, 2015, p.244).

Ainda segundo a autora, nesse período o planejamento ocorria de forma burocrática e mecânica, sem análise da realidade e seus problemas e sem um comprometimento por parte dos professores com a sua transformação. Investigando sobre as escolas de Educação Básica em São Paulo a autora destacou que, "é possível perceber, ainda hoje, em algumas escolas e em alguns momentos, práticas de planejamentos semestrais dos docentes relacionadas a essas características".

Por outro lado, o excesso de demandas laborais dos docentes - incluindo atividades de ensino, pesquisa, extensão e gestão - concorre para a redução do tempo, e até mesmo do desejo, de trabalhar de forma coletiva. Para esses docentes, conforme pesquisa realizada por ARRUDA (2015), o tempo dedicado as encontros coletivos é mais bem aproveitado na resolução das urgências do curso, visto que, por vezes, nos espaços de discussão coletiva ocorrem debates inócuos, esvaziados do verdadeiro sentido do planejamento participativo. Diante do exposto, acreditamos que nem sempre o trabalho coletivo é uma tarefa fácil. A própria reunião dos sujeitos em um espaço comum exige esforço, considerando as diferentes demandas de trabalho de cada um. Ademais, divergências de concepções, opiniões, anseios e metas podem dificultar o diálogo e o estabelecimento de consenso entre os pares. Contudo, concordamos com o poeta João Cabral de Melo Neto quando ele diz que

um galo sozinho não tece uma manhã: ele precisará sempre de outros galos. De um que apanhe esse grito que ele e o lance a outro; de um outro galo que apanhe o grito de um galo antes e o lance a outro; e de outros galos que com muitos outros galos se cruzem os fios de sol de seus gritos de galo, para que a manhã, desde uma teia tênue, se vá tecendo, entre todos os galos. E se encorpando em tela, entre todos, se erguendo tenda, onde se entrem todos, se entretendo para todos, no toldo (a manhã) que plana livre de armação. A manhã, toldo de um tecido tão aéreo que, tecido, se leva por si: luz balão (NETO, 1965, s./p.). 
Assim, a despeito de todas as diferenças, o planejamento participativo exige o pensar junto e o abrir mão de metas individuais em prol das necessidades coletivas.

Nessa direção, nos questionamos sobre qual a importância atribuída ao planejamento no âmbito do Ensino Superior, mais especificamente, na UFTM. Por isso, buscamos compreender o significado do referido planejamento para os cursos desta instituição e, também, como se deu a primeira experiência de Planejamento Pedagógico Semestral pós-normatização institucional.

Feitas tais considerações, passamos à apresentação/discussão dos resultados encontrados.

\subsection{Planejamento Pedagógico Semestral nos cursos de graduação da UFTM}

A UFTM está sediada na cidade de Uberaba, na região do Triângulo Mineiro, em Minas Gerais, e oferta cursos nas áreas da Saúde, Ciências Humanas e Sociais, Licenciaturas e Tecnologias. Atualmente, são ofertados 28 cursos de graduação, dos quais 25 são ofertados no campus sede e 03 no campus situado no município de Iturama, também em Minas Gerais.

Para estes cursos foi elaborada a Decisão Normativa n. ${ }^{0}$ 24/2018, que instituiu o Planejamento Pedagógico Semestral no Calendário Acadêmico dos Cursos de Graduação da UFTM. Sua definição foi descrita como sendo um "espaço de reflexão, estudo e tomada de decisões para que gestores e docentes de cada curso pensem coletivamente ações pedagógicas visando à melhoria do processo ensino-aprendizagem" (UFTM, 2018, p.1).

A necessidade de instituir um espaço para que esse planejamento pedagógico acontecesse foi percebida nas reuniões do Conselho de Ensino ${ }^{5}$, nas quais vinha sendo destacada a necessidade de ampliação dos espaços destinados ao planejamento coletivo.

Assim, após a publicação da normativa, a experiência teve início no segundo semestre de 2018 para cursos ofertados em Iturama, e no primeiro semestre de 2019 para cursos ofertados em Uberaba, sendo esta última nosso objeto de investigação.

A coleta dos dados se deu por meio da análise de dois instrumentos, a saber, questionário semi-aberto e Relatório de Planejamento Pedagógico Semestral. A partir destes, passamos à análise e discussão dos dados.

\footnotetext{
${ }^{5}$ É um órgão consultivo e deliberativo, no que concerne às atividades de ensino de graduação e ensino básico, técnico e tecnológico, do qual fazem parte, dentre outros, os coordenadores de todos os cursos de graduação da UFTM.
} 


\section{MATERIAIS E MÉTODOS}

A presente investigação utilizou pesquisa bibliográfica e análise de documentos e dados referentes aos cursos de graduação da UFTM, campus sede, a saber: Biomedicina; Licenciatura em Ciências Biológicas; Educação Física; Enfermagem; Engenharia Ambiental; Engenharia Civil; Engenharia de Alimentos; Engenharia de Produção; Engenharia Elétrica; Engenharia Mecânica; Engenharia Química; Licenciatura em Física; Fisioterapia; Licenciatura em Geografia; Licenciatura em História; Licenciatura em Letras (Português/Inglês); Licenciatura em Letras (Português/Espanhol); Licenciatura em Educação do Campo; Licenciatura em Matemática; Medicina; Nutrição; Psicologia; Licenciatura em Química; Serviço Social; e Terapia Ocupacional.

Os instrumentos utilizados para coleta de dados foram questionário semiaberto e relatórios das reuniões de Planejamento Pedagógico Semestral, realizadas pelos cursos de graduação em fevereiro de 2019.

Os dados colhidos nesses dois instrumentos foram analisados à luz de referenciais teóricos que abordam a temática. Nesses referenciais destacam-se Arruda, Veiga, Prado, Parente, Machado, Vasconcellos, dentre outros, cujas ideias serão apresentadas a seguir.

\section{ANÁLISE DOS DADOS E RESULTADOS}

\subsection{Questionário semi-aberto}

O questionário semi-aberto, elaborado via 'Formulários Google', foi encaminhado via email para os coordenadores dos 25 cursos de graduação do campus sede da UFTM. Os coordenadores receberam o questionário por serem eles os responsáveis por coordenar o Planejamento Pedagógico Semestral no âmbito de seus cursos.

O questionário possuía 02 questões fechadas sobre a frequência dos planejamentos pedagógicos no âmbito do curso antes da publicação da normativa e também sobre a participação dos docentes no primeiro encontro pós-normativa. Havia mais 03 questões abertas que versavam sobre a percepção dos coordenadores dos cursos quanto à importância do planejamento pedagógico para o curso, bem como sobre o primeiro planejamento feito nos moldes da Decisão Normativa supracitada. Os coordenadores não deveriam se identificar ou identificar o curso. 
Após envio do questionário às coordenações dos cursos, obtivemos 15 respostas, por meio das quais verificamos, primeiramente, que 53,3\% dos cursos participantes da pesquisa não realizavam atividades de planejamento pedagógico coletivo no âmbito do curso. Quanto aos demais cursos, $20 \%$ realizavam planejamentos pedagógicos anuais e $26,7 \%$ já trabalhavam com planejamentos pedagógicos semestrais. Um dos participantes da pesquisa informou que seu curso não realizou o Planejamento Pedagógico Semestral coletivo em 2019, não justificando o motivo.

Verifica-se, portanto, que para metade destes cursos de graduação esta foi a primeira experiência de planejamento pedagógico coletivo. Apesar disso, todos os coordenadores responderam que endentem que o Planejamento Pedagógico Semestral é importante para a melhoria do processo ensino-aprendizagem no âmbito do curso. No entanto, algumas respostas apontaram que a efetividade do planejamento depende da participação de todos os docentes.

De fato, compreendemos que o planejamento pedagógico coletivo e participativo é essencial para o processo ensino-aprendizagem, pois sem ele corre-se o risco de deixar predominar o "laissezfaire, o caminhar conforme as ondas, ou o andar conforme a conspiração dos ventos" (GESSER, 2011, p.16 apud ARRUDA, 2015, p.247). Por isso, é importante que, institucionalmente, possa haver espaços para a discussão da temática "planejamento", com vistas a estabelecer uma cultura de tomada de decisões coletivas no âmbito do curso, especialmente no que se refere às questões pedagógicas. Assim, o planejamento pode, de fato, contribuir com as práticas e superar um caráter meramente burocrático de atendimento a normativas institucionais.

A participação dos sujeitos é o que dá significado ao planejamento, pois permite que o grupo se identifique e se comprometa de forma mais efetiva com aquilo que foi pensado coletivamente. "Que valor pode ter um pedaço de papel escrito? A teoria quando assumida por um grupo, transforma-se em "força material” (VASCONCELLOS, 2007, p.172). Por isso, no questionário, alguns coordenadores reafirmaram que, apesar de entenderem a importância do planejamento pedagógico, acreditam que seus resultados seriam mais efetivos caso houvesse maior participação dos docentes.

Creio que para que haja uma contribuição efetiva todos devem participar ativamente, ainda há um longo processo para ser feito (Curso 15, 2019).

Neste aspecto, 33,3\% dos coordenadores afirmaram que houve participação de poucos docentes, $33,3 \%$ disseram que houve presença de metade dos docentes e 33,3\% informaram que 
contaram com boa parte dos docentes. Um dos cursos informou, ainda, que houve a participação de alunos no processo e outro curso salientou que a presença destes seria importante.

Ainda sobre a participação dos docentes no planejamento pedagógico:

A ideia é muito boa, entretanto, não foi tão eficaz quanto poderia ser uma vez que apenas os docentes do departamento do curso participaram. Como muitos docentes de outros que atuam no curso são de outros departamentos, nenhum deles esteve presente na reunião. $\mathrm{O}$ fato de alguns docentes atuarem em vários cursos em um semestre pode ter provocado esse não comparecimento, uma vez que a participação em todos os encontros para Planejamento Pedagógico Semestral de todos os cursos onde atuam, é inviável considerando o volume de trabalho dos docentes na universidade (Curso 7, 2019).

A resposta transcrita acima demonstra um dos possíveis motivos pelos quais há baixa participação de docentes em momentos destinados ao planejamento pedagógico coletivo: sobrecarga de trabalho. Entende-se, portanto, que a ausência de docentes nos momentos destinados ao planejamento pedagógico nem sempre é devida ao desprestígio da atividade de planejar coletivamente (ARRUDA, 2015), mas pode resultar do excesso de atividades docentes para atender a diferentes cursos de graduação, além da pesquisa e da extensão.

Mais uma vez, destaca-se a importância da articulação entre cursos e instâncias superiores da universidade, para que, coletivamente, busquem formas de melhorar a participação dos docentes nestes momentos de planejamento, favorecendo as reflexões teórico-filosóficas relacionadas à temática. É preciso planejar com consciência do que se está fazendo e do porquê se está fazendo.

A partir destas reflexões coletivas, podem ser traçadas estratégias para superar as dificuldades encontradas pelos cursos para realizar o Planejamento Pedagógico Semestral. Quanto a isso, a principal dificuldade citada pelos coordenadores dos cursos no questionário foi justamente a adesão dos professores, em especial daqueles que atendem a diversos cursos. A outra dificuldade citada foi relacionada às datas definidas no Calendário Acadêmico para a atividade de planejamento. Segundo as respostas, as datas foram estabelecidas deixando pouco tempo hábil para divulgação da atividade, bem como desconsiderando que muitos docentes ainda estavam de férias.

Apesar das dificuldades elencadas e da participação não tão satisfatória de docentes, os coordenadores informaram, de modo geral, que o planejamento contribui para: (a) organização do curso; (b) definição de estratégias; (c) discussão de questões relacionadas às metodologias de ensinoaprendizagem e avaliação; (d) definição de ações para reduzir índices de retenção e a evasão; (e) diagnóstico de problemas de infraestrutura e (f) diálogo e interação interdisciplinar entre os docentes. 
Estes elementos foram mais bem apresentados nos Relatórios de Planejamento Pedagógico, e serão analisados no próximo tópico.

Por último, ao avaliarem esta primeira experiência de planejamento pós-normatização, 13 dos 15 coordenadores afirmaram que a experiência foi positiva. Destacamos algumas considerações:

Bastante pertinente por conta de termos um momento de parada para repensarmos e planejarmos ações que viabilizam o bom aproveitamento dos conteúdos e a formação do discente (Curso 12, 2019).

O encontro foi entre poucos professores, mas aproveitamos para discutir o caráter que o planejamento poderia tomar para ajudar no desenvolvimento do curso (Curso 6, 2019).

Críticas ao processo foram feitas, novamente, em relação às datas estipuladas para a atividade e quanto à obrigatoriedade do planejamento:

Avalio como positivo, embora considero a obrigatoriedade desnecessária uma vez que realizamos mensalmente reunião do Colegiado do Curso, reunião de Departamento, reunião do NDE e da Clínica escola. Intercalados sempre as quartas feiras (Curso 11, 2019).

Ainda no questionário, foi citado que 05 dos 25 cursos do campus sede fizeram o Planejamento Pedagógico Semestral juntos, por pertencerem a um mesmo Instituto Acadêmico. No entanto, "poucos professores participaram. Seria interessante a presença de professores dos outros Institutos que oferecem disciplinas para o curso" (Curso 2, 2019). Participaram deste encontro 26 docentes pertencentes aos 05 cursos.

Consideramos importante que os sujeitos avaliem se, neste encontro coletivo, foram consideradas as demandas específicas de cada curso, seus Projetos Pedagógicos e outras especificidades. Em uma primeira avaliação, foi relatado:

O retorno dos professores em relação à atividade de planejamento realizada foi muito positivo. Foi possível estabelecer um clima de confiança, respeito e humanidade, em que os professores puderam apresentar suas angústias, dificuldades, expectativas (Curso 10, 2019).

Assim, percebe-se que a atividade de planejamento pedagógico foi percebida como algo positivo e necessário no âmbito dos cursos, porém sua efetividade depende, sobretudo, da participação dos docentes dos cursos, o que demanda esforços coletivos e articulados entre as diversas instâncias da universidade. 


\subsection{Relatórios do Planejamento Pedagógico Semestral}

Os Relatórios de Planejamento Pedagógico Semestral encaminhados pelos cursos do campus sede à Pró-Reitoria de Ensino/Divisão de Apoio Técnico-Pedagógico da UFTM ${ }^{6}$ continham as temáticas abordadas e os encaminhamentos dados nas reuniões de planejamento. $\mathrm{O}$ documento foi constituído por dois Eixos, a saber, Eixo I - Organização Didático-Pedagógica e Eixo II Infraestrutura.

Por meio dos relatórios foi possível verificar, novamente, o registro da necessidade de maior participação de docentes no planejamento pedagógico, em especial de docentes que atendem a mais de um curso na instituição, tendo em vista que cada curso tem demandas e necessidades específicas.

O que é importante, do ponto de vista do ensino, é deixar claro que o professor necessita planejar, refletir sobre sua ação, pensar sobre o que faz, antes, durante e depois. $\mathrm{O}$ ensino superior tem características muito próprias porque objetiva a formação do cidadão, do profissional, do sujeito enquanto pessoa, enfim de uma formação que o habilite ao trabalho e à vida (LEAL, 2005, p. 12).

Também foi possível observar que o espaço destinado ao planejamento pedagógico favoreceu discussões e encaminhamentos diretamente relacionados aos PPC e aos seus elementos e materialização. Foram abordadas questões relacionadas ao currículo (disciplinas, cargas horárias, ementas, etc), às metodologias de ensino-aprendizagem, às formas de avaliação, dentre outros, perpassando discussões sobre retenção e evasão, papel social das profissões, dentre outros.

Muitos encaminhamentos demonstraram a necessidade de articulação entre cursos e demais instâncias da instituição, confirmando que o sucesso de qualquer planejamento depende do comprometimento e da união de esforços entre os sujeitos, no âmbito do curso e para além dele. Quanto a isso, um dos relatórios enfatizou que "a dimensão pedagógica dos cursos da UFTM carece de maior apoio, seja no instituto, seja com melhores condições implementadas pela gestão institucional" (Relatório 1, 2019).

\footnotetext{
${ }^{6}$ É um órgão da Pró-Reitoria de Ensino da UFTM responsável pelo assessoramento pedagógico aos cursos de graduação.
} 


\section{CONSIDERAÇÕES FINAIS}

Em uma era de incertezas e constantes transformações, o planejamento se faz ainda mais essencial a quaisquer atividades humanas, especialmente as ligadas à formação dos sujeitos. Assim, no âmbito educacional, defendemos que o ato de planejar deve envolver todos os níveis do processo ensino-aprendizagem e, no caso dos cursos de graduação, precisa estar presente desde a concepção do curso até a materialização do currículo em sala de aula ou outros espaços de aprendizagem.

Mais que uma atividade burocrática, o planejamento - seja por meio do PPC, Planos de Ensino, Planejamento Pedagógico ou outro - permite que se conheça de forma mais profunda a realidade e que se trace caminhos para sua transformação. Planejamento que se faz e refaz constantemente, que permite a (re)invenção e o (re)planejar, não com um fim em si mesmo, mas almejando um futuro intencional.

É importante conceber o ato de planejar como uma atitude científica, pautada não somente na previsão do que irá acontecer, mas também, em um processo de reflexão e análise sobre a própria prática docente, sobre o fazer pedagógico contínuo e diário (LEAL, 2005).

Para tanto, é importante que os atores educacionais - docentes, discentes, gestores, servidores administrativos e comunidade - tenham sensibilidade para perceber como as nuances internas $^{7}$ e externas ${ }^{8}$ podem interferir no alcance das metas e objetivos traçados. É por meio da observação atenta e da avaliação permanente que os sujeitos poderão verificar o que deve ser modificado, a fim de que não se corra o risco de esvaziar o ato educativo, na medida em que as práticas educacionais não espelhem as concepções que orientam os modos de ser e fazer do coletivo.

Foi nesse sentido que a Decisão Normativa n. ${ }^{\circ}$ 24/2018, a qual instituía que o Planejamento Pedagógico, em todos os cursos de graduação da UFTM, deveria ser realizado antes do início de cada semestre letivo, fosse alterado em reunião do Conselho de Ensino (COENS). Desse modo, foi definido que o prazo para o planejamento pedagógico se daria dentro do primeiro mês letivo de cada semestre, considerando as condições do tempo e do espaço institucional como fatores essenciais para tal modificação.

\footnotetext{
${ }^{7}$ Referem-se à dinâmica da própria instituição educativa. Englobam as ações voltadas à organização, gestão, gerenciamento de recursos e à cultura institucional.

${ }^{8}$ Dizem respeito à realidade social mais ampla. Envolvem as políticas educacionais globais, nacionais, locais e, também, os ditames e demandas socioeconômicas vigentes.
} 
Sabe-se que o planejamento é algo que deve ser pensando dentro das demandas e limites institucionais. Ou seja, métodos e técnicas devem ser selecionados e organizados de acordo com os objetivos do ensino, sendo, portanto, flexíveis.

Tal concepção de planejamento só se materializa com a participação consciente e intencional dos sujeitos, sendo este um dos principais entraves percebidos para a realização do Planejamento Pedagógico Semestral na universidade que constituiu nosso campo de pesquisa.

É preciso refletir sobre o papel do planejamento nos cursos de graduação e sobre a importância desse planejamento acontecer de maneira participativa. Para isso, acreditamos na importância da reflexão coletiva, da socialização de experiências e na transformação de concepções na busca pelo comprometimento de cada um em prol do coletivo.

\section{REFERÊNCIAS}

ALARCÃO, Isabel. Prefácio. In: BROILO, Cecília Luiza. Assessoria pedagógica na universidade: (com) formando o trabalho docente. Araraquara: Junqueira e Marin, 2015.

ARRUDA, Heloisa Paes de Barros. Planejamento e plano de aula na educação: histórico e a prática de dois professores. Educativa, Goiânia, v.18, n.1, jan./jun. 2015.

BRASIL. Resolução CONAES n. ${ }^{\circ}$ 01, de 17 de junho de 2010. Institui o Núcleo Docente Estruturante. Brasília, 2010.

HAAS, Célia Maria. Projetos pedagógicos nas instituições de educação superior: aspectos legais na gestão acadêmica. RBPAE - v.26, n.1, p.151-171, jan./abr. 2010.

LEAL, Regina Barros. Planejamento de ensino: peculiaridades significativas. Revista Iberoamericana de Educación, Fortaleza, v. 37, n.3, 1-7, 2005. Disponível em: $<$ https://rieoei.org/RIE/article/view/2705>. Acesso em: 25 jul. 2019.

MACHADO, Nilson José. Educação: projetos e valores. 6.ed. São Paulo: Escrituras Editora, 2006.

MORIN, Edgar. A cabeça bem-feita: repensar a reforma, reformar o pensamento. Tradução Eloá Jacobina. 9. ed. Rio de Janeiro: Bertrand Brasil, 2004.

NETO, João Cabral de Melo. A educação pela pedra. São Paulo: Nova Fronteira, 1965.

PARENTE, José. Planejamento estratégico na educação. 3.ed. Brasília: Liber Livro, 2010. 
PRADO, Maria Elisabette Brisola Brito. Pedagogia de projetos: fundamentos e implicações. In: ALMEIDA, Maria Elizabeth Bianconcini de; MORAN, José Manuel (Org.). Integração das tecnologias na educação. Brasília: Ministério da Educação/SEED/TV Escola/Salto para o Futuro, 2005. cap. 1, artigo 1.1, p. 12-17.

UFTM. Decisão Normativa n. ${ }^{\text {o } 24 / 2018 . ~ U b e r a b a: ~ U F T M, ~} 2018$ a.

UFTM. Minuta do PPI/UFTM 2017-2021. Uberaba: UFTM, 2018 b.

VASCONCELLOS, Celso dos Santos. Planejamento: projeto de ensino-aprendizagem e projeto político pedagógico. São Paulo: Libertad Editora, 2007.

VEIGA, Ilma Passos. (Org.). Projeto político-pedagógico da escola: uma construção possível. Campinas: Papirus, 2004.

VEIGA, Ilma Passos. (Org.). Projeto político-pedagógico da escola: uma construção possível. 14. ed. Campinas: Papirus, 2002. Disponível em:

http://nead.uesc.br/arquivos/Biologia/modulo_7_bloco_4/TEXTO.3-VEIGA-ILMAPASSOS-PPP-UMA-CONSTRUCAO-COLETIVA.pdf. Acesso em: 14 mar. 2019. 